University of Warwick institutional repository: http://go.warwick.ac.uk/wrap This paper is made available online in accordance with publisher policies. Please scroll down to view the document itself. Please refer to the repository record for this item and our policy information available from the repository home page for further information.

To see the final version of this paper please visit the publisher's website. Access to the published version may require a subscription.

Author(s): T. D. Veal, P. D. C. King, S. A. Hatfield, L. R. Bailey, C. F. McConville, B. Martel, J. C. Moreno, E. Frayssinet, F. Semond, and J. Zúñiga-Pérez

Article Title: Valence band offset of the ZnO/AIN heterojunction determined by x-ray photoemission spectroscopy

Year of publication: 2008

Link to published version:

http://dx.doi.org/ 10.1063/1.3032911

Publisher statement: None 


\title{
Valence band offset of the ZnO/AIN heterojunction determined by $x$-ray photoemission spectroscopy
}

\author{
T. D. Veal, ${ }^{1, a)}$ P. D. C. King, ${ }^{1}$ S. A. Hatfield ${ }^{1}$ L. R. Bailey, ${ }^{1}$ C. F. McConville, ${ }^{1}$ B. Martel, ${ }^{2}$ \\ J. C. Moreno, ${ }^{2}$ E. Frayssinet, ${ }^{2}$ F. Semond, ${ }^{2}$ and J. Zúñiga-Pérez ${ }^{2}$ \\ ${ }^{1}$ Department of Physics, University of Warwick, Coventry CV4 7AL, United Kingdom \\ ${ }^{2}$ Centre de Recherche sur l'Hétéro-Epitaxie et ses Applications, Centre National de la Recherche \\ Scientifique, Parc de Sophia Antipolis, Rue Bernard Grégory, 06560 Valbonne, France
}

(Received 30 September 2008; accepted 3 November 2008; published online 20 November 2008)

\begin{abstract}
The valence band offset of $\mathrm{ZnO} / \mathrm{AlN}$ heterojunctions is determined by high resolution $\mathrm{x}$-ray photoemission spectroscopy. The valence band of $\mathrm{ZnO}$ is found to be $0.43 \pm 0.17 \mathrm{eV}$ below that of AlN. Together with the resulting conduction band offset of $3.29 \pm 0.20 \mathrm{eV}$, this indicates that a type-II (staggered) band line up exists at the $\mathrm{ZnO} / \mathrm{AlN}$ heterojunction. Using the III-nitride band offsets and the transitivity rule, the valence band offsets for $\mathrm{ZnO} / \mathrm{GaN}$ and $\mathrm{ZnO} / \mathrm{InN}$ heterojunctions are derived as 1.37 and $1.95 \mathrm{eV}$, respectively, significantly higher than the previously determined values. (C) 2008 American Institute of Physics. [DOI: 10.1063/1.3032911]
\end{abstract}

$\mathrm{ZnO}$ is of interest in a range of current research areas as a result of its wide band gap $(\sim 3.3 \mathrm{eV}$ at $300 \mathrm{~K})$ and particularly high exciton binding energy $(60 \mathrm{meV}) .{ }^{1}$ Since excitons are stable at room temperature, $\mathrm{ZnO}$ is very attractive for the realization of optoelectronic devices based on cavitycoupled polariton lasers operated at room temperature. ${ }^{2-4}$ Other promising optoelectronic device applications include blue and green light emitting diodes, ${ }^{5-7}$ where $\mathrm{ZnO}$ can be used either as the active region or as a transparent contact.

Combinations of $\mathrm{ZnO}$ and III-N materials have considerable potential for heterostructure devices as a result of their high epitaxial compatibility (wurtzite structures with lattice mismatches between $-4 \%$ and $9 \%$ ) and the range of band gaps available using III-N binary and ternary materials (from $\sim 0.7$ to $\sim 6.2 \mathrm{eV}){ }^{8}$ Most work on hybrid oxide/nitride systems to date has focused on $\mathrm{ZnO} / \mathrm{GaN},{ }^{9,10}$ but in order to fully exploit these materials other combinations must be explored.

For heterostructure devices, knowledge of the valence and conduction band offsets of the different material combinations is of particular importance. The III-N/III-N hetreojunction band offsets have been determined by x-ray photoemission spectroscopy (XPS), ${ }^{11,12}$ with type-I (straddling) band line-ups being found in all cases, as predicted from $a b$ initio calculations ${ }^{13,14}$ and charge neutrality level arguments. ${ }^{12,15,16}$

Of the $\mathrm{ZnO} / \mathrm{III}-\mathrm{N}$ heterojunctions, $\mathrm{ZnO} / \mathrm{InN}$ (Ref. 17) and $\mathrm{ZnO} / \mathrm{GaN}$ (Ref. 18) band offsets have been measured and show type-I and type-II junctions, respectively. While these junction types are in agreement with theoretical studies, as discussed later, the actual values of the valence band offsets seem to be too low when compared with the predictions of both previous theory and the transitivity rule. ${ }^{14,19-21}$ The band offsets of the $\mathrm{ZnO} / \mathrm{AlN}$ combination have not previously been investigated experimentally. In this letter, high resolution XPS has been used to directly determine the valence band offset between $\mathrm{ZnO}$ and AlN.

Three samples were used for the XPS experiments: a 550-nm-thick $\mathrm{ZnO}$ layer grown on a 25 -nm-thick low tem-

${ }^{a)}$ Electronic mail: tim.veal@physics.org. perature (LT)-grown $\mathrm{ZnO}$ buffer layer on $c$-plane sapphire, a $250 \mathrm{~nm}$ layer of AlN grown on $\mathrm{Si}(111)$, and $5 \mathrm{~nm}$ of $\mathrm{ZnO}$ on $250 \mathrm{~nm}$ of AlN grown on $\mathrm{Si}(111)$. The $\mathrm{ZnO}$ was grown by radio frequency plasma-assisted molecular-beam epitaxy (MBE), as described elsewhere, ${ }^{22}$ at $\sim 500{ }^{\circ} \mathrm{C}$ for the "thick" $\mathrm{ZnO}$ layer and $\sim 370{ }^{\circ} \mathrm{C}$ for the LT-buffer and $5 \mathrm{~nm}$ layer. The AlN was grown at $\sim 910{ }^{\circ} \mathrm{C}$ by $\mathrm{MBE}$ using ammonia as the nitrogen source. ${ }^{23}$

XPS was performed at the National Centre for Electron Spectroscopy and Surface Analysis, Daresbury Laboratory, U.K., using a Scienta ESCA300 spectrometer with a monochromated rotating anode $\mathrm{Al} K \alpha$ x-ray source, providing a high intensity $1486.7 \mathrm{eV}$ line. Photoelectrons are detected by a $300 \mathrm{~mm}$ radius concentric hemispherical analyzer with a multichannel detector. XPS data were recorded at room temperature with a resolution of $0.45 \mathrm{eV}$. Binding energies are calibrated using the Fermi edge of an $\mathrm{Ar}^{+}$-ion bombarded silver sample.

The thickness of the $\mathrm{ZnO}$ film in the $\mathrm{ZnO} / \mathrm{AlN}$ sample was determined by the ratio of the epilayer and substrate photoemission peak areas, taking into account appropriate atomic sensitivity factors and inelastic mean free paths. ${ }^{24}$ The calculated epilayer thickness was $5 \pm 1 \mathrm{~nm}$, in agreement with the value obtained from the estimated growth rate.

$\mathrm{Zn} 2 p_{3 / 2}$ and $\mathrm{Al} 2 p$ XPS spectra are shown in Figs. 1(a) -1 (d) fitted using Shirley backgrounds and Voigt (mixed Lorentzian-Gaussian) functions, the parameters for which are shown in Table I. The $\mathrm{Zn} 2 p_{3 / 2}$ spectrum of both the $\mathrm{ZnO}$ and the $\mathrm{ZnO} / \mathrm{AlN}$ samples and the $\mathrm{Al} 2 p$ spectrum of the AlN sample were fitted by a single contribution, attributed to the bonding configurations $\mathrm{Zn}-\mathrm{O}$ and $\mathrm{Al}-\mathrm{N}$, respectively. However, for the $\mathrm{Al} 2 p$ spectrum of the $\mathrm{ZnO} / \mathrm{AlN}$ sample [Fig. 1(d)], an additional low intensity higher binding energy component was also required. This extra component is attributed to $\mathrm{Al}-\mathrm{O}$ bonding at the $\mathrm{ZnO} / \mathrm{AlN}$ interface and/or inelastic losses to free carriers in the $\mathrm{ZnO}$ layer, as recently observed in photoemission of $\mathrm{InN} .^{25}$

The valence band XPS spectra for the thick layer $\mathrm{ZnO}$ and AlN samples are shown in Figs. 1(e) and 1(f). The position of the valence band maximum (VBM) with respect to the surface Fermi level was determined by the intersection of 

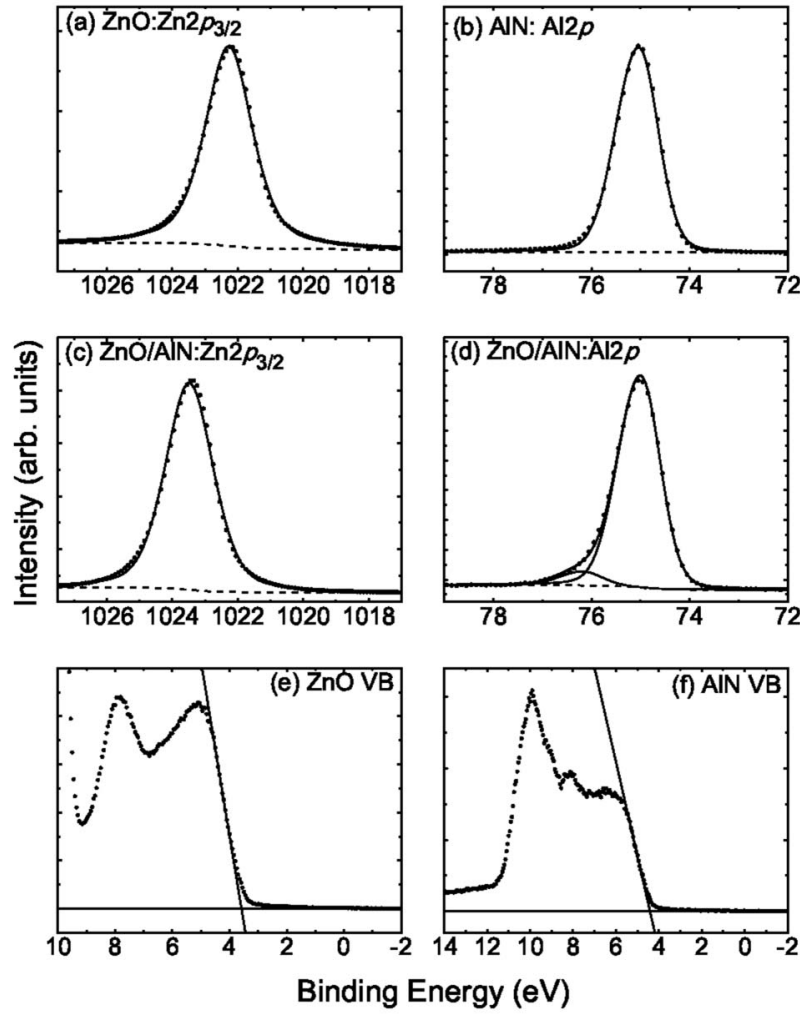

FIG. 1. $\mathrm{Zn} 2 p_{3 / 2}$ XPS spectra for (a) $\mathrm{ZnO}$ and (c) $\mathrm{ZnO} / \mathrm{AlN}$ samples, and $\mathrm{Al}$ $2 p$ XPS spectra for (b) AlN and (d) $\mathrm{ZnO} / \mathrm{AlN}$ samples. Experimental data points are fitted by Voigt (mixed Lorentzian-Gaussian) lineshapes (solid lines) after the application of a Shirley background (dashed line). Also shown are valence band spectra for (e) $\mathrm{ZnO}$ and (f) AlN. The peak and VBM positions are summarized in Table I.

linear fits to the leading edge of the valence band photoemission and the background. ${ }^{26}$ The VBM positions are shown in Table I.

The valence band offset of the $\mathrm{ZnO} / \mathrm{AlN}$ heterojunction was determined from the energy separation between the core levels in the $\mathrm{ZnO} / \mathrm{AlN}$ sample and the VBM to core level separations in the thick layer $\mathrm{ZnO}$ and AIN samples, as described by

$$
\begin{aligned}
E_{\mathrm{VBO}}= & E_{\mathrm{Zn} 2 p_{3 / 2}}^{\mathrm{ZnO} / \mathrm{AlN}}-E_{\mathrm{Al} 2 p}^{\mathrm{ZnO} / \mathrm{AlN}}-\left(E_{\mathrm{Zn} 2 p_{3 / 2}}^{\mathrm{ZnO}}-E_{\mathrm{VBM}}^{\mathrm{ZnO}}\right) \\
& +\left(E_{\mathrm{Al} 2 p}^{\mathrm{AlN}}-E_{\mathrm{VBM}}^{\mathrm{AlN}}\right),
\end{aligned}
$$

where $E_{i}^{s}$ denotes the energy of feature $i$ in sample $s$. The $\mathrm{Zn}$ $2 p_{3 / 2}$ and $\mathrm{Al} 2 p$ core levels have been used in Eq. (1), but equally the $\mathrm{O} 1 s$ and $\mathrm{N} 1 s$ peaks can be used. Indeed, from the results given in Table II, it can be seen that valence band offsets calculated for all four combinations of core levels are

TABLE I. Binding energies (in eV) of the XPS peaks and VBM for the $\mathrm{ZnO}, \mathrm{AlN}$, and $\mathrm{ZnO} / \mathrm{AlN}$ samples. Energies are referenced to the Fermi level $(0 \mathrm{eV})$. The errors in the peak positions and VBM are \pm 0.05 and $\pm 0.10 \mathrm{eV}$, respectively.

\begin{tabular}{lccr}
\hline \hline & ZnO & AlN & ZnO/AlN \\
\hline Zn $2 p_{3 / 2}$ & 1022.27 & $\ldots$ & 1023.48 \\
O $1 s$ & 531.03 & $\ldots$ & 532.22 \\
$\mathrm{Al} 2 p$ & $\ldots$ & 74.94 & 74.90 \\
$\mathrm{~N} 1 s$ & $\ldots$ & 398.25 & 398.23 \\
$\mathrm{VBM}$ & 3.58 & 4.38 & 4.80 \\
\hline \hline
\end{tabular}

TABLE II. Valence band offset values (in eV) determined for a $\mathrm{ZnO} / \mathrm{AlN}$ heterojunction using various combinations of XPS core levels. All values correspond to the VBM of $\mathrm{ZnO}$ being below that of AlN. The error in each value is $\pm 0.17 \mathrm{eV}$.

\begin{tabular}{lcc}
\hline \hline & $\mathrm{Al} 2 p$ & $\mathrm{~N} 1 s$ \\
\hline Zn $2 p$ & 0.45 & 0.43 \\
$\mathrm{O} 1 s$ & 0.43 & 0.41 \\
\hline \hline
\end{tabular}

well within experimental error of one another, and place the $\mathrm{ZnO} \mathrm{VBM} 0.43 \pm 0.17 \mathrm{eV}$ below that of AlN. Using the room temperature band gaps for $\mathrm{ZnO}$ and $\mathrm{AlN}$ [3.30 (Ref. 1) and $6.16 \mathrm{eV}$ (Ref. 27), respectively], the $\mathrm{ZnO} / \mathrm{AlN}$ heterojunction is found to have a type-II (staggered) band line-up, as shown in Fig. 2, with a corresponding conduction band offset of $3.29 \pm 0.20 \mathrm{eV}$.

Using the previously determined valence band offsets of the wurtzite III-nitrides [0.58 eV for InN/GaN (Ref. 12) and $1.52 \mathrm{eV}$ for InN/AlN (Ref. 11)] and applying the transitivity rule $^{28}$ allows the valence band offsets of $\mathrm{ZnO}$ with $\mathrm{GaN}$ and $\mathrm{InN}$ to be derived. Values of $1.37 \mathrm{eV}$ for $\mathrm{ZnO} / \mathrm{GaN}$ and 1.95 $\mathrm{eV}$ for $\mathrm{ZnO} / \mathrm{InN}$ are thus obtained, as depicted in Fig. 2. These are significantly higher than the values previously determined of $0.8 \mathrm{eV}$ for $\mathrm{ZnO} / \mathrm{GaN}$ (Ref. 18) and $0.82 \mathrm{eV}$ for InN/ZnO. ${ }^{17}$ One or both of these values must be incorrect because the InN/GaN valence band offset ${ }^{12}$ is known to be much greater than $0.02 \mathrm{eV}$.

The value of $0.8 \mathrm{eV}$ for $\mathrm{ZnO} / \mathrm{GaN}$ of Hong et al. ${ }^{18}$ is unreliable due to the use of a combination of ultraviolet photoemission spectroscopy to determine the VBM positions and XPS to determine the core-level positions, while different references were used to calibrate the binding energy scale for the two techniques. Moreover, the Ga $3 d$ and $\mathrm{Zn} 3 d$ shallow core levels were used, which are inappropriate for determining a valence band offset ${ }^{12}$ because they hybridize with the valence band, forming part of the band structure. Along with the uncertainty introduced by spectral broadening due to the use of nonmonochromated x-rays, this means that the result of Hong et al. ${ }^{18}$ must be treated with caution. The XPS-determined value of $0.82 \mathrm{eV}$ for $\mathrm{InN} / \mathrm{ZnO}$ of Zhang et $a l .{ }^{17}$ is also questionable due to a combination of neither the $\mathrm{ZnO}$ nor the InN valence band photoemission spectra exhibiting the expected shape for an anion $2 p$-dominated valence

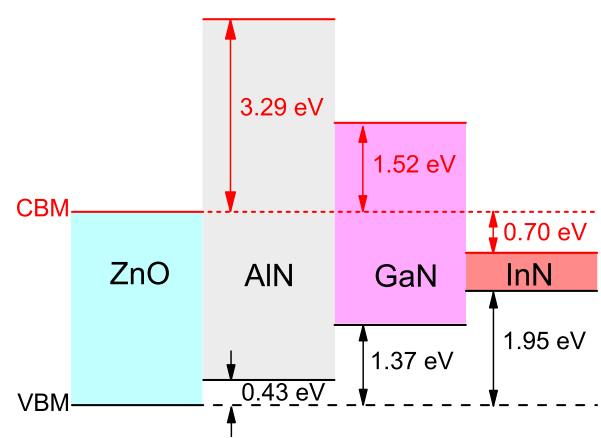

FIG. 2. (Color online) The room temperature VBM and conduction band minimum line-up of the $\mathrm{ZnO} / \mathrm{AlN}$ heterojunction, showing a type-II band alignment. The band line-ups with $\mathrm{GaN}$ and $\mathrm{InN}$ are also shown. These are derived from the previously determined valence band offsets of the III-Ns (Refs. 11 and 12) and the transitivity rule (Ref. 28) The room temperature band gaps of $3.45 \mathrm{eV}$ for GaN (Ref. 27) and $0.65 \mathrm{eV}$ for InN (Ref. 31) were used to derive the depicted conduction band offsets with $\mathrm{ZnO}$. 
band $d^{29,30}$ and the poor In $3 d$ peak fitting, where components of very different widths have been used to fit the In $3 d_{5 / 2}$ and In $3 d_{3 / 2}$ lines.

In conclusion, the valence band offset between $\mathrm{ZnO}$ and AlN has been determined by XPS to be $0.43 \pm 0.17 \mathrm{eV}$, with a type II band line-up. The corresponding conduction band offset is $3.29 \mathrm{eV}$. Additionally, III-nitride offsets and the transitivity rule have been used to derive valence band offsets of $1.37 \mathrm{eV}$ for $\mathrm{ZnO} / \mathrm{GaN}$ and $1.95 \mathrm{eV}$ for $\mathrm{ZnO} / \mathrm{InN}$, indicating that previously determined values are too low. These are important quantities for the design of hybrid II-O/III-N devices. For example, the large conduction band and valence band offsets reported here are sufficient to provide significant electron and hole confinement potentials for hybrid $\mathrm{ZnO} / \mathrm{III}-\mathrm{N}$ heterostructures. Importantly, the confining potentials can also be tuned by varying the III-N alloy composition.

The authors would like to thank Danny Law and Graham Beamson of the NCESS facility at Daresbury Laboratory for technical assistance with XPS measurements. Also, the Engineering and Physical Sciences Research Council, U.K., is acknowledged for financial support under Grant Nos. EP/ E010210/1 and EP/C535553/1 and for access to the NCESS facility under Grant No. EP/E025722/1. The French Agence Nationale de la Recherche is acknowledged for financial support under the research program ZOOM.

${ }^{1}$ Ü. Özgür, Y. I. Alivov, C. Liu, A. Teke, M. A. Reshchikov, S. Doğan, V. Avrutin, S. J. Cho, and H. Morkoç, J. Appl. Phys. 98, 041301 (2005).

${ }^{2}$ M. Zamfirescu, A. Kavokin, B. Gil, G. Malpuech, and M. Kaliteevski, Phys. Rev. B 65, 161205 (2002).

${ }^{3}$ M. Mihailovic, A.-L. Henneghien, S. Faure, P. Disseix, J. Leymarie, A. Vasson, D. A. Buell, F. Semond, C. Morhain, and J. Zuniga-Pérez, "Optical and excitonic properties of $\mathrm{ZnO}$ films," Opt. Mater. (Amsterdam, Neth.) (to be published), doi:10.1016/j.optmat.2007.10.023.

${ }^{4}$ J. Kasprzak, M. Richard, S. Kundermann, A. Baas, P. Jeambrun, J. M. J. Keeling, F. M. Marchetti, M. H. Szymańska, R. André, J. L. Staehli, V. Savona, P. B. Littlewood, B. Deveaud, and L. S. Dang, Nature (London) 443, 409 (2006)

${ }^{5}$ A. Tsukazaki, A. Ohtomo, T. Onuma, M. Ohtani, T. Makino, M. Sumiya, K. Ohtani, S. F. Chichibu, S. Fuke, Y. Segawa, H. Ohno, H. Koinuma, and M. Kawasaki, Nature Mater. 4, 42 (2005).

${ }^{6}$ Z. P. Wei, Y. M. Lu, D. Z. Shen, Z. Z. Zhang, B. Yao, B. H. Li, J. Zhang,
D. X. Zhao, X. W. Fan, and Z. K. Tang, Appl. Phys. Lett. 90, 042113 (2007).

${ }^{7}$ C. Bayram, F. Hosseini Teherani, D. J. Rogers, and M. Razeghi, Appl. Phys. Lett. 93, 081111 (2008).

${ }^{8}$ J. Wu, W. Walukiewicz, K. M. Yu, W. Shan, J. W. Ager III, E. E. Haller, H. Lu, W. J. Schaff, W. K. Metzger, and S. Kurtz, J. Appl. Phys. 94, 6477 (2003a).

${ }^{9}$ Y. A. Alivov, J. E. Van Nostrand, D. C. Look, M. V. Chukichev, and B. M. Ataev, Appl. Phys. Lett. 83, 2943 (2003).

${ }^{10}$ D. J. Rogers, F. Hosseini Teherani, A. Yasan, K. Minder, P. Kung, and M. Razeghi, Appl. Phys. Lett. 88, 141918 (2006).

${ }^{11}$ P. D. C. King, T. D. Veal, P. H. Jefferson, C. F. McConville, T. Wang, P. J. Parbrook, H. Lu, and W. J. Schaff, Appl. Phys. Lett. 90, 132105 (2007).

${ }^{12}$ P. D. C. King, T. D. Veal, C. E. Kendrick, L. R. Bailey, S. M. Durbin, and C. F. McConville, Phys. Rev. B 78, 033308 (2008)

${ }^{13}$ S.-H. Wei and A. Zunger, Appl. Phys. Lett. 69, 2719 (1996).

${ }^{14}$ C. G. Van de Walle and J. Neugebauer, Appl. Phys. Lett. 70, 2577 (1997).

${ }^{15}$ J. Robertson and B. Falabretti, J. Appl. Phys. 100, 014111 (2006).

${ }^{16}$ W. Mönch, J. Appl. Phys. 80, 5076 (1996).

${ }^{17}$ R. Zhang, P. Zhang, T. Kang, H. Fan, X. Liu, S. Yang, H. Wei, Q. Zhu, and Z. Wang, Appl. Phys. Lett. 91, 162104 (2007).

${ }^{18}$ S.-K. Hong, T. Hanada, H. Makino, H.-J. Ko, Y. Chen, A. Tanaka, H. Saski, S. Sato, D. Imai, K. Araki, and M. Shinohara, J. Vac. Sci. Technol. B 19, 1429 (2001).

${ }^{19}$ W. Mönch, Appl. Phys. Lett. 86, 162101 (2005).

${ }^{20}$ J. von Pezold and P. D. Bristowe, J. Mater. Sci. 40, 3051 (2005).

${ }^{21}$ M. W. Wang, J. O. McCaldin, J. F. Swenberg, T. C. McGill, and R. J. Hauenstein, Appl. Phys. Lett. 66, 1974 (1995).

${ }^{22}$ F. Vigué, P. Vennéguès, C. Deparis, S. Vézian, M. Laügt, and J.-P. Faurie, J. Appl. Phys. 90, 5115 (2001).

${ }^{23}$ F. Semond, Y. Cordier, N. Grandjean, F. Natali, B. Damilano, S. Vézian, and J. Massies, Phys. Status Solidi A 188, 501 (2001).

${ }^{24}$ S. Tanuma, J. Powell, and D. R. Penn, Surf. Interface Anal. 21, 165 (1993).

${ }^{25}$ P. D. C. King, T. D. Veal, H. Lu, S. A. Hatfield, W. J. Schaff, and C. F. McConville, Surf. Sci. 602, 871 (2008).

${ }^{26}$ S. A. Chambers, T. Droubay, T. C. Kaspar, and M. Gutowski, J. Vac. Sci. Technol. B 22, 2205 (2004).

${ }^{27}$ I. Vurgaftman and J. R. Meyer, J. Appl. Phys. 94, 3675 (2003)

${ }^{28}$ S.-H. Wei and A. Zunger, Appl. Phys. Lett. 72, 2011 (1998).

${ }^{29}$ L. Ley, R. A. Pollak, F. R. McFreely, S. P. Kowalczyk, and D. A. Shirley, Phys. Rev. B 9, 600 (1974).

${ }^{30}$ P. D. C. King, T. D. Veal, C. F. McConville, F. Fuchs, J. Furthmüller, F. Bechstedt, J. Schörmann, D. J. As, K. Lischka, H. Lu, and W. J. Schaff, Phys. Rev. B 77, 115213 (2008).

${ }^{31}$ J. Wu, W. Walukiewicz, W. Shan, K. M. Yu, J. W. Ager III, S. X. Li, E. E. Haller, H. Lu, and W. J. Schaff, J. Appl. Phys. 94, 4457 (2003). 